\title{
Representación Bimodal de Valores Cardinales en la Comprensión de los Primeros Números
}

\section{Bimodal Representation of Cardinal Values in the Comprehension of the First Numbers}

\author{
Jimena Rodríguez y Analía Salsa \\ Consejo Nacional de Investigaciones Científicas y Técnicas de Argentina
}

\begin{abstract}
En 2 estudios se indagó si y cómo la presentación bimodal de información cuantitativa impacta en la comprensión y el uso de los valores cardinales 1 a 6 por parte de niños preescolares. Se utilizó un diseño transversal correlacionalcausal, conformándose una muestra por conveniencia de 108 niños de 3 y 4 años de cuatro jardines de infantes privados de la zona céntrica de la ciudad de Rosario, Argentina. Los niños de ambos grupos etarios resolvieron la tarea Dame un Número, en el Estudio 1 con palabras número y en el Estudio 2 con colecciones de objetos y en imágenes (condición unimodal iterativa) y con objetos e imágenes junto con sus correspondientes palabras número (condición bimodal). A través de pruebas estadísticas no paramétricas (prueba Kruskal-Wallis, prueba U de MannWhitney, prueba Chi Cuadrado, prueba de rangos de Wilcoxon), los resultados mostraron que los modos bimodales, en comparación con los unimodales, ampliaron de 2 a 4 el tamaño de las colecciones que los niños de 3 años fueron capaces de construir y de 3 a 6 a los 4 años. La modalidad semiótica es un factor clave al presentar y expresar información cuantitativa cuando los niños preescolares resuelven problemas que involucran números.
\end{abstract}

Palabras clave: representación bimodal, palabras número, objetos, imágenes, niños

Two studies examined whether and how the bimodal presentation of quantitative information impacts on preschoolers' comprehension and use of cardinal values from 1 to 6 . A correlational-causal cross-sectional design was used, with a convenience sample comprising 1083 - and 4-year-old children from four private kindergartens located in central Rosario, Argentina. Children of both age groups solved the Give-a-Number task, in Study 1 with number words and in Study 2 with sets of objects and pictures (iterative unimodal condition), as well as with objects and pictures combined with number words (bimodal condition). Non-parametric tests (Kruskal-Wallis test, U MannWhitney test, Chi Square test, Wilcoxon rank test) showed that bimodal modes, in comparison with the unimodal ones, increased the size of the sets that the participants were able to build from 2 to 4 at age 3 and from 3 to 6 at age 4. When presenting and expressing quantitative information, semiotic modality is a key factor for preschoolers to solve problems involving numbers.

Keywords: bimodal representation, number words, objects, pictures

En su vida cotidiana, los niños interactúan con diferentes representaciones de la cantidad: palabras número (en la modalidad oral y escrita), numerales arábigos, gestos numéricos y colecciones de objetos tridimensionales y en imágenes. Estas representaciones externas no son solo soportes del número, sino que, en tanto elementos constitutivos de nuestra cognición, actúan como organizadores del conocimiento numérico (Martí \& Scheuer, 2015; Rodríguez, Martí \& Salsa, 2016); desde un enfoque multimodal (Kress, 2010), son modos semióticos distintos que habilitan y potencian procesos de significación y resignificación del número.

Sin embargo, la mayor parte de las investigaciones en desarrollo numérico temprano se ha centrado en la comprensión del significado cardinal de las palabras número orales (en adelante, para simplificar, usaremos la expresión palabras número para la forma de representación de la cantidad anclada en el lenguaje oral) y su uso en tareas de cuantificación de objetos como ¿Cuántos hay? y Dame un Número (Gelman \& Gallistel, 1978; Le Corre \& Carey, 2007; Sarnecka \& Carey, 2008; Sarnecka \& Lee, 2009; Spaepen, Gunderson, Gibson, Goldin-Meadow \& Levine, 2018; van Marle, Chu, Li \& Geary, 2014; Wynn, 1990, 1992, 2018). Estos estudios muestran que las primeras cuatro palabras número se adquieren en orden, una a la vez, aproximadamente entre los 2 y 4 años. Cuando los niños comprenden y usan el significado cardinal de

Jimena Rodríguez y Analía Salsa, Instituto Rosario de Investigaciones en Ciencias de la Educación, Consejo Nacional de Investigaciones Científicas y Técnicas y Universidad Nacional de Rosario, Argentina.

Esta investigación fue financiada por la Agencia Nacional de Promoción Científica y Tecnológica en el marco del proyecto PICT $2017 \mathrm{~N}^{\circ} 3199$ bajo la dirección de la segunda autora. Las autoras agradecen a los niños y docentes que participaron en la investigación.

La correspondencia relativa a este artículo debe ser dirigida a Analía Salsa, IRICE (CONICET-UNR), Bv. 27 de Febrero 210 bis, Rosario, Argentina. E-mail: salsa@irice-conicet.gov.ar 
una palabra número (tres) pero no de la siguiente en la lista de conteo (cuatro), se encontrarían en una etapa específica del conocimiento cardinal ("conocedor de tres"); cuando no asignan una palabra número a ninguna colección de elementos estarían en el nivel "no conocedor" y, más allá del cuatro, en el nivel "conocedor cardinal" (Carey, 2009; Sarnecka, 2015; Wynn, 1992). En este enfoque, la comprensión del significado cardinal de una palabra número es un indicador privilegiado del conocimiento de la cantidad, desestimando la variedad de modos semióticos que los niños usan para representar, comunicar y resolver problemas que involucran números. El interés de los estudios que aquí presentamos radica en el uso de objetos e imágenes, junto con las palabras número, en los primeros pasos del conocimiento cardinal.

Las palabras número y las colecciones de objetos y en imágenes poseen diferentes propiedades en tanto representaciones de la cantidad. Mientras que las palabras número son representaciones efímeras, las imágenes y los objetos son representaciones permanentes (Martí, 2012; Rodríguez et al., 2016). Las primeras se despliegan en el tiempo, por lo cual necesitan ser interpretadas en el momento de su producción y no pueden ser utilizadas más adelante. En cambio, las representaciones permanentes tienen una naturaleza concreta que permite su manipulación y uso en nuevos contextos o situaciones.

Las palabras también se diferencian de las imágenes y los objetos por el modo en que denotan la cantidad: un único signo representa un valor cardinal, no existiendo correspondencia entre su forma y la cantidad de elementos de la colección. Por el contrario, las imágenes y los objetos son representaciones iterativas (tres marcas gráficas o tres tapas denotan el valor cardinal tres); la relación con el referente está motivada, es una relación en sentido literal o figurativo (Martí, 2012; Tolchinsky, 2003).

Otra cuestión a considerar es que las imágenes y los objetos, al ser representaciones permanentes, tienen una naturaleza doble: son objetos con determinadas propiedades físicas $y$, simultáneamente, formas de representación que remiten a algo distinto a ellas. Para usar simbólicamente una imagen o un objeto, los niños precisan activar al mismo tiempo las representaciones mentales de estas dos dimensiones, lo que DeLoache (1995) ha denominado representación dual. Sin embargo, a diferencia de las imágenes, cuando los objetos en una colección son perceptualmente atractivos y con funciones instrumentales variadas, los niños podrían tener dificultades a la hora de comprender el significado cardinal de la colección (Uttal, Liu \& DeLoache, 2006; Uttal, O'Doherty, Newland, Hand \& DeLoache, 2009).

En la última década, diversas investigaciones han comenzado a focalizar su interés en los efectos de las formas de representar la cantidad en los conocimientos numéricos tempranos. Esta perspectiva supone un desarrollo del número no lineal, concretado a través de trayectorias sensibles, no solo a la edad de los niños, sino también a la modalidad semiótica en la que se presenta y expresa la información cuantitativa. Mientras que distintos estudios examinaron el desempeño de niños preescolares en tareas de cuantificación, comparando palabras número y gestos numéricos (por ejemplo, tres dedos para el valor cardinal tres) (Gibson, Gunderson, Spaepen, Levine \& Goldin-Meadow, 2019; Gunderson, Spaepen, Gibson, Goldin-Meadow \& Levine, 2015; Nicoladis, Pika \& Marentette, 2010) y palabras número y numerales arábigos (Benoit, Lehalle, Molina, Tijus \& Jouen, 2013; Hurst, Anderson \& Cordes, 2017; Jiménez Lira, Carver, Douglas \& LeFevre, 2017), hasta nuestro conocimiento únicamente dos estudios abordaron el uso de imágenes y objetos como representaciones de los primeros números.

Petersen et al. (2014), empleando un diseño pre y post-test, compararon los efectos de cinco sesiones de práctica de conteo con libros ilustrados y objetos en las habilidades de conteo de niños de 3,5 años y en su comprensión de la cardinalidad. Las experiencias de conteo de imágenes mejoraron el desempeño en la tarea Dame un Número; las experiencias contando ejemplares tridimensionales de los objetos representados en los libros no tuvieron impacto en el rendimiento post-test. Los autores interpretaron estos resultados en términos de la hipótesis de la representación dual (DeLoache, 1995): los objetos promueven una focalización de la atención de los niños en sus propiedades físicas, obstaculizando la comprensión de la cardinalidad como un atributo importante de las colecciones.

En una investigación reciente (Rodríguez, Martí \& Salsa, 2018) examinamos el impacto de tres representaciones de la cantidad en el desempeño de niños de 3, 3,5 y 4 años en la tarea Dame un Número. Solicitamos a los niños la construcción de colecciones de 1 a 6 elementos no solo a partir de la información cuantitativa con soporte en las palabras número de la experimentadora ("Dame tres galletas") (Wynn, 1990, 1992), sino además mediante colecciones de objetos (tapas de botella) e imágenes (círculos dibujados en tarjetas). Los niños resolvieron la tarea con los tres modos semióticos por separado, contrabalanceado el orden de presentación de los objetos y las imágenes y administrando las palabras número siempre en tercer lugar. Los resultados muestran una influencia clara de la modalidad semiótica en el desempeño infantil. Las 
imágenes, en comparación con las palabras número, favorecieron la construcción de colecciones de 3 elementos a los 3 años, mientras que tanto las imágenes como los objetos, en comparación con las palabras, favorecieron la construcción de colecciones de 3 elementos a los 3,5 años y de colecciones de tamaño 4 a los 4 años. Las imágenes y los objetos, por su naturaleza permanente e iterativa, serían modos semióticos más sensibles para poner en juego conocimientos cardinales emergentes en el aprendizaje de una palabra número y la siguiente y no desempeños absolutos ligados a etapas fijas del conocimiento.

Ahora bien, en nuestro estudio previo, los niños usaron cada una de las representaciones por separado. No obstante, en las actividades cotidianas, raramente un modo semiótico se utiliza en forma aislada. Los seres humanos estamos constantemente expuestos y hacemos uso de combinaciones de modalidades semióticas con la intención de producir sentido y comunicarlo a otros (Kress, 2010). Por lo tanto, nuestra pregunta en los estudios que aquí presentamos fue si y cómo la representación bimodal de valores cardinales, a través de colecciones de objetos y en imágenes junto con su correspondiente palabra número, influiría en el desempeño a los 3 y 4 años en la tarea Dame un Número.

Nuestra pregunta se fundamenta en al menos dos líneas de investigación. Por un lado, estudios en aprendizaje multimedia postulan que los estudiantes aprenden más eficazmente cuando la información verbal y visual se integra temporal y espacialmente (Mayer, 2002). Este supuesto, conocido como principio de contigüidad, ha sido empleado para argumentar cómo los aprendices pueden realizar conexiones significativas entre conceptos y una mejor integración y retención de la información cuando estímulos verbales y gráficos (Mayer \& Moreno, 2003) o verbales y gestuales (Congdon, Kwon \& Levine, 2018; Congdon et al., 2017) se presentan al mismo tiempo.

Por otro lado, ya en el dominio numérico, los niños no solo necesitan adquirir conocimientos sobre cómo las representaciones externas han de ser usadas para denotar valores cardinales, sino también sobre los mapeos o asociaciones entre ellas, específicamente, cómo cada palabra número se asocia a un numeral y cómo las palabras número y los numerales se asocian a cantidades exactas presentadas, por ejemplo, en colecciones en imágenes (Benoit et al., 2013; Jiménez Lira et al., 2017). De hecho, Hurst et al. (2017) señalan que los niños aprenden el significado de las palabras número asociándolas a cantidades exactas, de una manera similar a la representación bimodal de valores cardinales del presente estudio. Los conocimientos sobre estos mapeos y acerca del uso de distintas representaciones de la cantidad se relacionan con el conteo, la cardinalidad y habilidades más complejas, como las comparaciones numéricas simbólicas (elegir entre dos palabras número cuál representa una mayor o menor cantidad) (Jiménez Lira, 2016).

Las experiencias en el hogar podrían jugar un papel importante en las habilidades tempranas para mapear palabras número y colecciones. Mix et al. (Mix, 1999, 2002; Mix, Sandhofer \& Baroody, 2005) plantean que, en estas experiencias, cuando los niños observan y escuchan que dos colecciones de objetos se etiquetan de la misma manera, con una única palabra número, se favorecería el reconocimiento de la cantidad como un atributo común de ambas colecciones de objetos. Al construir y comparar colecciones, las palabras número también podrían funcionar como una ayuda para la memoria. Por ejemplo, los niños usarían la palabra número que representa la cantidad de elementos de una colección como soporte, mientras seleccionan o construyen una colección equivalente, en lugar de realizar la laboriosa tarea de comparar uno a uno los elementos de los dos conjuntos.

Realizamos dos estudios con el fin de indagar los efectos de la combinación de dos modos semióticos al presentar a los niños cantidades discretas y pequeñas (1 a 6). El objetivo específico del Estudio 1 fue identificar los valores cardinales que niños de 3 y 4 años comprenden y usan cuando resuelven la tarea Dame un Número únicamente con palabras número. En base a investigaciones previas (Baroody, Lai \& Mix, 2017, Octubre; Le Corre \& Carey, 2007; Rodríguez et al., 2018; Sarnecka \& Carey, 2008), nuestra hipótesis fue que los niños de 3 años podrían construir correctamente colecciones de hasta 2 elementos y los de 4 años hasta 3; en consecuencia, los valores cardinales 3 y 4 estarían en proceso de elaboración en cada uno de estos grupos etarios.

El objetivo del Estudio 2 fue comparar los efectos de la presentación unimodal, pero permanente e iterativa (imágenes y objetos), y la bimodal (imágenes/palabras número y objetos/palabras número) en el desempeño general en la tarea Dame un Número y, específicamente, en los valores cardinales emergentes a los 3 y 4 años. En base a estudios previos (Rodríguez et al., 2018; Salsa \& Martí, 2015), nuestras hipótesis fueron dos. Primero, la presentación unimodal con imágenes y objetos, en comparación con las palabras número, amplía el tamaño de las colecciones que los niños pueden construir, facilitando la construcción de colecciones de 3 elementos a los 3 años y de 4 elementos a los 4 años. Segundo, la presentación bimodal, en comparación con las unimodales (palabras número y representaciones iterativas), tiene un efecto aún más 
beneficioso: facilita la construcción de colecciones de hasta 4 elementos en el grupo de 3 años y de colecciones de tamaño 5 en el grupo de 4 años.

\section{Estudio 1}

\section{Método}

Diseño. Teniendo en cuenta los objetivos de la investigación, en los Estudios 1 y 2 empleamos un diseño transversal correlacional-causal.

Participantes. Trabajamos con una muestra por conveniencia de 36 niños de dos grupos de edad, 3 años ( $n=18 ; 9$ niñas) y 4 años ( $n=18 ; 9$ niñas). El promedio de edad en el grupo de 3 años fue de 36,14 meses $(D E=0,89)$ y en el de 4 años, 47,70 meses $(D E=0,97)$.

Contactamos a los niños a través de sus instituciones educativas, cuatro jardines de infantes de gestión privada de la zona céntrica de la ciudad de Rosario (Santa Fe, Argentina), donde concurren niños de nivel socioeconómico (NSE) medio. La restricción en el NSE se fundamenta en investigaciones previas que han documentado la influencia de esta variable en los conocimientos numéricos tempranos (e.g., Anders et al., 2012; Martí, Scheuer, Cavalcante, Trench \& Brizuela, 2016). Los niños no contaban con antecedentes de trastornos en su desarrollo cognitivo y/o del lenguaje, de acuerdo con los registros de las instituciones educativas.

Materiales y procedimiento. Utilizamos una colección de 16 galletas (diámetro: $6 \mathrm{~cm}$ ), un plato (diámetro: $25 \mathrm{~cm}$ ) y un títere (Winnie Pooh).

Respecto de los resguardos éticos, aplicamos los procedimientos recomendados por las asociaciones profesionales internacionales en relación al trabajo y la observación con niños y los principios establecidos por la Convención Internacional sobre los Derechos del Niño. Realizamos reuniones informativas en los jardines de infantes, con la presencia de personal directivo, docentes y padres, para informar los detalles y requerimientos de los estudios y solicitamos a los padres autorizar en forma escrita la participación de los niños, asegurándoles confidencialidad de la información.

Entrevistamos a los niños en forma individual en una sala disponible del jardín de infantes al que concurrían. La primera autora de este artículo ofició de experimentadora en todos los casos. La sesión completa duraba aproximadamente 15 minutos. La tarea propuesta fue una adaptación del procedimiento diseñado en Salsa y Martí (2015), pero usando una única modalidad semiótica, las palabras número. Luego de algunos minutos de juego libre para propiciar un vínculo de confianza con la experimentadora, invitábamos al niño a jugar con el títere y las galletas. La tarea Dame un Número comenzaba con una fase previa de orientación.

Fase previa. Su objetivo fue centrar la atención del niño en el dominio numérico y explicitar el propósito de la tarea: poner en el plato una cantidad determinada de galletas. En primer lugar, la experimentadora preguntaba al niño si sabía contar y explicaba que Winnie Pooh todavía no había aprendido los números. Luego, colocaba 10 galletas sobre una mesa y pedía al niño que las contara en voz alta para enseñar los números al títere. Si el niño no iniciaba el conteo, la experimentadora comenzaba la serie numérica ("Uno, dos, tres..."), señalando cada galleta. Aunque las habilidades de conteo no fueron consideradas como criterio de exclusión para la conformación de la muestra, todos los niños fueron capaces de contar sin errores hasta seis.

Después del conteo, la experimentadora ponía sobre la mesa el plato y las 16 galletas diciendo "Vas a ayudar a Winnie Pooh a poner galletas en el plato. Recuerda que él todavía no sabe contar. Si Winnie Pooh quiere poner en el plato una galleta para ti y una galleta para mí, ¿cuántas galletas tienes que poner en el plato?" Si el niño no respondía o lo hacía incorrectamente, la experimentadora explicaba "Si Winnie Pooh quiere poner en el plato una galleta para ti y otra para mí, haría así (mientras coloca dos galletas). Esta es para ti y esta es para mí (señalando cada galleta)".

Dame un Número. Al comienzo de la tarea la experimentadora explicaba al niño que Winnie Pooh solicitaría, usando una palabra número, que él o ella colocara una cantidad determinada de galletas en el plato: "Winnie Pooh me va a decir en el oído el número de galletas que quiere que tú pongas en el plato [mirando al títere y acercando el oído a su boca]. Winnie Pooh quiere que pongas cuatro galletas en el plato". En cada ensayo se retiraban las galletas del plato para que la colección de 16 galletas permaneciera constante en el transcurso de la tarea. Los errores de los niños no se corregían. La experimentadora solicitaba la 
construcción de las colecciones de 1 a 6 elementos, en un orden sin progresión ascendente ni descendente, comenzando con el 1. Cuando el niño no era exitoso al colocar en el plato $N$ galleta/s, la experimentadora solicitaba en el siguiente ensayo $N-1$ galleta/s antes de pedir nuevamente la cantidad incorrecta. Si el niño producía $N$ en forma correcta una vez y en forma incorrecta otra, se solicitaba esa cantidad una tercera vez. De este modo, la tarea finalizaba cuando el niño daba correctamente $N$ galleta/s dos veces o cuando construía todas las colecciones solicitadas hasta el 6 sin errores.

Codificación y análisis de los datos. Videograbamos las sesiones experimentales y luego las transcribimos textualmente para su codificación y análisis. La tarea Dame un Número se utiliza comúnmente como medida del conocimiento sobre el significado cardinal, exacto y único, de las palabras número. En cada ensayo, codificamos la respuesta del niño como correcta (si colocaba en el plato la cantidad solicitada de galletas) o incorrecta. Las respuestas incorrectas se codificaron como errores próximos (una galleta de más o de menos) o errores distantes (dos o más galletas de más o de menos). Esta estrategia de análisis, que combina respuestas correctas y un gradiente de respuestas incorrectas, nos permite poner en evidencia tensiones y desfases en el desarrollo numérico temprano, con significados cardinales disponibles para los niños, como así también conocimientos parciales o emergentes.

En relación con el objetivo de nuestro primer estudio, analizamos las respuestas correctas en función del tamaño de las colecciones, construyendo siete categorías que reflejan el patrón de desempeño de los niños en el transcurso de la tarea:

- No conocedor: niños que no construyeron correctamente ninguna colección de elementos (al menos dos veces).

- Conocedor de uno: niños que construyeron, sin errores, únicamente colecciones de tamaño 1.

- Conocedor de dos: niños que construyeron, sin errores, colecciones de tamaño 1 y 2.

- Conocedor de tres (a seis): niños que construyeron, sin errores, colecciones de 1, 2 y 3. Aplicamos el mismo criterio para las colecciones de tamaño 4, 5 y 6.

Cabe destacar que no empleamos la categoría conocedor cardinal para la construcción exitosa de colecciones desde 4 elementos porque, a diferencia de estudios previos (Le Corre, Van de Walle, Brannon \& Carey, 2006; Wynn, 1990, 1992), la construcción de colecciones de 4 elementos no garantizó en nuestra muestra respuestas correctas también en los tamaños 5 y 6 .

Para los análisis estadísticos aplicamos pruebas no paramétricas, dado que el estadístico KolgomorovSmirnov mostró que la distribución de contraste no se ajustaba a la normal ( $p<0,05$ en todos los casos). Para estimar la asociación entre el desempeño en la tarea y la edad aplicamos un análisis estadístico de comparación de frecuencias (prueba de Chi Cuadrado). En ambos estudios utilizamos el programa estadístico SPSS $®$ versión 20.

Análisis preliminares que realizamos con la prueba $U$ de Mann-Whitney indicaron la ausencia de efectos del sexo en el desempeño infantil, tanto en el grupo de 3 años, $U=36, p=0,650$, como en el de 4 años, $U=32,50, p=0,435$. Por lo tanto, no consideramos esta variable en el resto de los análisis.

\section{Resultados}

Analizamos los datos en dos etapas. Primero realizamos un análisis del desempeño infantil al interior de cada grupo de edad (3 y 4 años) y posteriormente entre grupos, con el fin de identificar los valores cardinales (entre 1 y 6) disponibles y emergentes en cada grupo etario.

De los 18 niños entrevistados en el grupo de 3 años (ver Tabla 1), la mayor parte (67\%) se desempeñó como conocedor de dos, construyendo sin errores colecciones de 1 y 2 elementos. Aunque solo el $11 \%$ de los niños fue capaz de construir colecciones de hasta 3 elementos, las respuestas incorrectas del grupo revelarían la naturaleza emergente de este valor cardinal: el 64\% de los errores fueron próximos, esto es, los niños colocaron 2 o 4 galletas al solicitarles 3 (en comparación con el 36\% de errores distantes). Por el contrario, a pesar de que también solo el $11 \%$ de los niños se desempeñó como conocedor de 4 , con este valor cardinal la proporción de errores distantes (69\%) fue superior a la proporción de errores próximos (31\%).

Los niños del grupo de 4 años se desempeñaron, en mayor medida, como conocedores de tres (56\%), de modo similar a lo que observamos en los niños más pequeños. Cuando los niños de 4 años construyeron colecciones de tamaño 4, el 67\% de las respuestas incorrectas del grupo fueron errores próximos (en comparación con el 33\% de errores distantes). Los resultados confirman un incremento con la edad en el 
tamaño de las colecciones que los niños pueden construir, de 2 a 3 elementos, utilizando la información cuantitativa de las palabras número del adulto.

Tabla 1

Desempeño en la Tarea Dame un Número con Palabras Número, Según Grupo de Edad

\begin{tabular}{lcccccc}
\hline \multirow{2}{*}{ Desempeño por valor cardinal } & \multicolumn{2}{c}{ Cantidad de niños ${ }^{1}$} & & & \\
\cline { 2 - 3 } & 3 años & 4 años & & $\chi^{2}$ & & \\
\hline No conocedor & 1 & 0 & & 1,02 & 1 & 0,310 \\
Conocedor de uno & 1 & 1 & - & - & - \\
Conocedor de dos & 12 & 3 & 9,25 & 1 & 0,002 \\
Conocedor de tres & 2 & 10 & 8,00 & 1 & 0,005 \\
Conocedor de cuatro & 2 & 3 & & 0,23 & 1 & 0,630 \\
Conocedor de cinco & 0 & 0 & & - & - & - \\
Conocedor de seis & 0 & 1 & 1,02 & 1 & 0,310 \\
\hline
\end{tabular}

${ }^{1}$ Sobre un total de 18 niños en cada grupo de edad.

En suma, nuestros datos indican patrones de desempeño en los niños de 3 y 4 años semejantes a los que han sido reportados en estudios previos, considerando solo respuestas correctas (Le Corre \& Carey, 2007; Le Corre et al., 2006; Sarnecka \& Lee, 2009; Wynn, 1990, 1992) como el interjuego entre respuestas correctas e incorrectas (Rodríguez et al., 2018; Salsa \& Martí, 2015). El desempeño con palabras número sirve como punto de partida del Estudio 2 para examinar si y cómo modos unimodales de presentación de la información cuantitativa, pero con representaciones permanentes e iterativas (colecciones de objetos y en imágenes) y modos bimodales (objetos e imágenes junto con sus correspondientes palabra número), serían soportes semióticos más eficaces, ampliando el tamaño de las colecciones que los niños pueden construir en la tarea Dame un Número.

\section{Estudio 2}

\section{Método}

Participantes. Participaron 72 niños de dos grupos de edad: 3 años $(n=36$, edad: $M=35,86$ meses, $D E=0,54)$ y 4 años $(n=36, M=47,76$ meses, $D E=0,66)$. Los niños asistían a los mismos jardines de infantes del Estudio 1 y los seleccionamos con una muestra por conveniencia. Al interior de cada grupo de edad asignamos aleatoriamente a los niños a dos condiciones: presentación unimodal y presentación bimodal. Cada condición quedó conformada con igual cantidad de niñas y niños.

Materiales. Además de las galletas, el plato y el títere que utilizamos en el Estudio 1, usamos seis tapas de botella de color negro (diámetro: $3,80 \mathrm{~cm}$, altura: $1,20 \mathrm{~cm}$ ) (de aquí en adelante "objetos") y seis tarjetas blancas $(9 \times 15 \mathrm{~cm})$ con círculos negros dibujados (diámetro: $2 \mathrm{~cm}$ ) que variaron en número de 1 a 6 y tenían una disposición irregular ("imágenes").

Procedimiento. Al igual que en el Estudio 1, realizamos reuniones informativas con los padres y obtuvimos el consentimiento informado de participación. Entrevistamos a los niños individualmente en una sala tranquila de la institución educativa a la que asistían. Antes de la administración de la tarea Dame un Número llevamos a cabo la fase previa de orientación descrita en el Estudio 1. La sesión completa duraba aproximadamente 20 minutos.

Condición presentación unimodal (iterativa). Al comienzo de la tarea, la experimentadora explicaba al niño que Winnie Pooh utilizaría una imagen (o una colección de objetos) para mostrar el número de galletas que él o ella debía colocar en el plato: "Vamos a seguir poniendo galletas en el plato. Winnie Pooh nos va a mostrar el número de galletas que tienes que poner usando estos dibujos (o estas tapas). Mira con atención, Winnie Pooh quiere que pongas este número de galletas en el plato [mostrando al niño una imagen o 
distribuyendo sobre la mesa un conjunto de tapas]". Como en el Estudio 1, luego de cada ensayo, la experimentadora retiraba las galletas del plato para mantener constante la colección de 16 galletas. Cuando cambiaba la modalidad semiótica, la experimentadora decía: "Ahora Winnie Pooh te va a mostrar el número de galletas que tienes que poner en el plato, usando estas tapas [o estos dibujos]". Durante la administración de la tarea, en ningún momento la experimentadora utilizaba palabras número ni corregía los errores de los niños. Cada niño resolvió la tarea con los dos modos semióticos por separado, imágenes y objetos, contrabalanceando el orden de presentación, de manera tal que la mitad de los niños resolvió primero la tarea con imágenes y la otra mitad con objetos. Con cada modo semiótico propusimos a los niños la construcción de colecciones sucesivas del 1 al 6, empleando tres órdenes de presentación de las cantidades, ninguno en progresión ascendente o descendente (3-5-2-6-1-4; 2-4-1-6-3-5; 4-2-5-3-6-1). Por lo tanto, la tarea estuvo compuesta por dos bloques de seis ensayos, uno para cada modo semiótico (12 ensayos en total).

Condición presentación bimodal. Desarrollamos el procedimiento de la misma manera que en la condición unimodal, excepto porque presentamos simultáneamente, por un lado, las colecciones en imágenes con sus correspondientes palabras número y, por otro, las colecciones de objetos con sus palabras número. De este modo, luego de explicar al niño que las imágenes (o los objetos) mostraban cuántas galletas poner en el plato, la experimentadora decía: "Mira con atención. Winnie Pooh quiere que pongas dos galletas en el plato [presentando, al decir dos, la imagen o la colección de tapas]". Cada niño realizó dos bloques de seis ensayos cada uno, un bloque con imágenes y palabras número y otro bloque con objetos y palabras número (12 ensayos en total), contrabalanceándose el orden de presentación de los modos semióticos y de las cantidades de igual manera que en la condición presentación unimodal.

Codificación y análisis de los datos. Transcribimos las sesiones experimentales y codificamos las respuestas de los niños, correctas e incorrectas, empleando los criterios descriptos en el Estudio 1. Los niños podían obtener un puntaje de 0 a 6 respuestas correctas por modalidad semiótica (imágenes y objetos). En ambas condiciones experimentales, para el análisis de las respuestas correctas en función del tamaño de las colecciones, usamos las categorías construidas en el estudio anterior, considerando el tamaño máximo de las colecciones que los niños construían correctamente con imágenes y objetos (por ejemplo, el conocedor de tres construyó colecciones de 1, 2 y 3 galletas usando imágenes y objetos).

Para los análisis estadísticos aplicamos pruebas no paramétricas (prueba Kruskal-Wallis, prueba U de Mann-Whitney, prueba Chi Cuadrado, prueba de rangos de Wilcoxon), dado que el estadístico KolgomorovSmirnov mostró que la distribución de contraste no se ajustaba a la normal ( $p<0,05$ en todos los casos). Para cada una de las comparaciones de a pares que resultaron significativas analizamos el tamaño del efecto mediante la prueba Delta de Cliff. Los análisis preliminares mediante la prueba U de Mann-Whitney mostraron que no hubo efectos del sexo, 3 años: $U=130, p=0,304,4$ años: $U=149, p=0,681$, ni del orden de presentación de los modos semióticos (objetos o imágenes) en el desempeño de los niños de ambos grupos de edad, 3 años: $U=157, p=0,872,4$ años: $U=113, p=0,107$.

\section{Resultados}

En este estudio, analizamos los datos en tres etapas. En primer lugar, realizamos un análisis al interior de cada grupo de edad (3 y 4 años) y luego entre grupos para estimar el impacto de la condición experimental (presentación unimodal iterativa versus bimodal) en el desempeño general con objetos e imágenes en la tarea Dame un Número. En segundo lugar, al interior de cada grupo de edad, centramos los análisis en los efectos de la condición experimental en función del tamaño de las colecciones solicitadas (entre 1 y 6). Finalmente, comparamos el desempeño de los niños en las tres condiciones experimentales (Estudio 1 versus Estudio 2) por valor cardinal y en cada grupo de edad.

Modos unimodales versus modos bimodales. Con respecto a los efectos del modo de presentación de la información cuantitativa al interior de cada grupo de edad (Figura 1), en el grupo de 3 años los resultados de la prueba $U$ de Mann-Whitney indican que en la condición bimodal los niños se desempeñaron mejor que en la condición unimodal cuando resolvieron la tarea con objetos (65\% versus $44 \%$ de respuestas correctas), $U=73, p=0,003$, Delta de Cliff $=-0,54$, como con imágenes, (65\% versus 50\%), $U=73, p=0,003$, Delta de Cliff $=-0,54$. Asimismo, no encontramos diferencias al comparar el desempeño en función de la modalidad semiótica (objetos versus imágenes) en ninguna de las dos condiciones experimentales, bimodal, prueba de rangos de Wilcoxon: $Z=0, p>0,999$, y unimodal, $Z=-1,32, p=0,186$. 


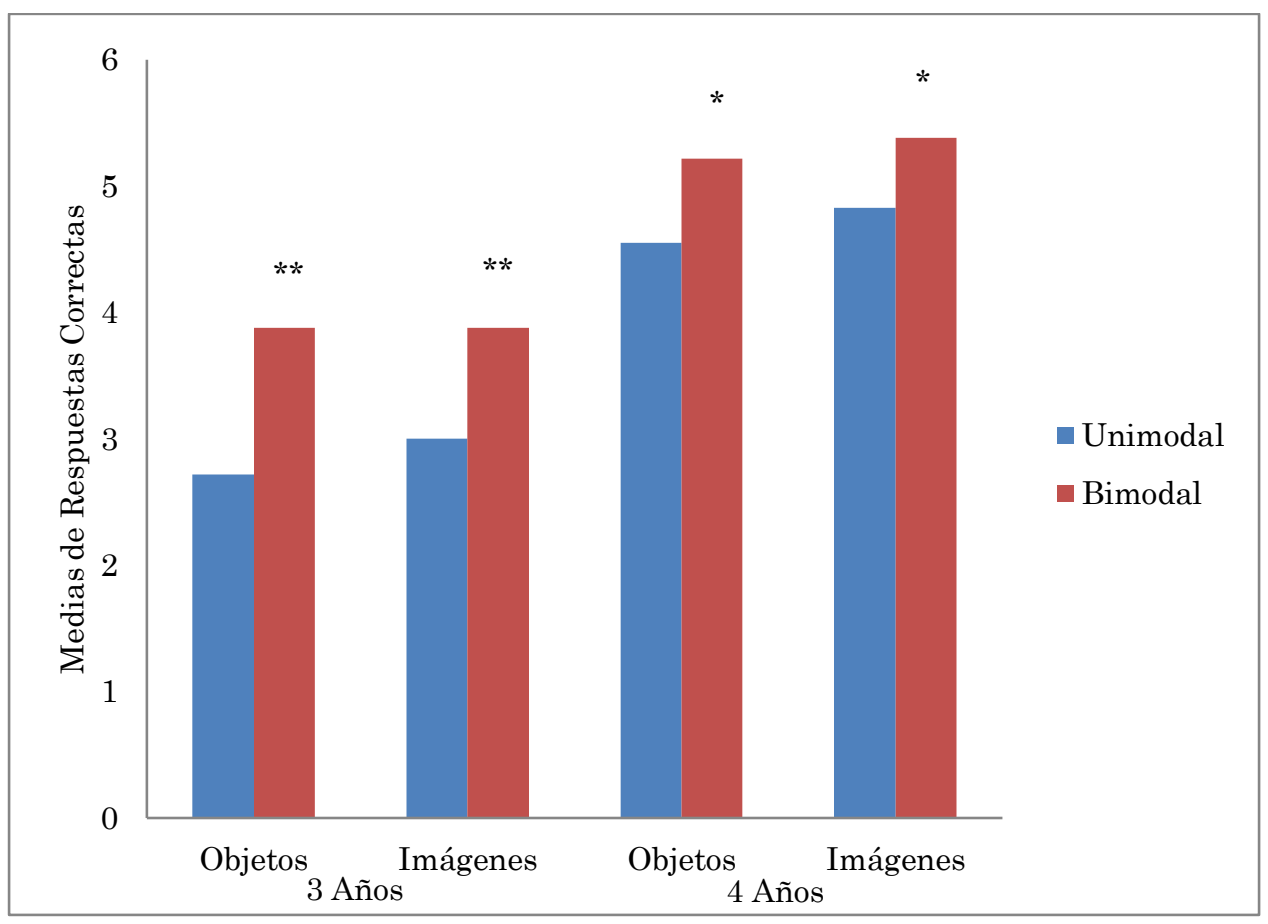

Figura 1. Desempeño en la tarea Dame un Número, según condición experimental (unimodal y bimodal) y grupo de edad (3 y 4 años). ${ }^{* *} p \leq 0,005$; $* p \leq 0,05$.

Un patrón de resultados similar observamos en el grupo de 4 años. El desempeño en las dos condiciones experimentales fue alto; sin embargo, en la condición bimodal, los niños se desempeñaron mejor que en la condición unimodal cuando trabajaron con objetos ( $87 \%$ versus $76 \%), U=92, p=0,017$, Delta de Cliff $=-0,34$, y con imágenes (90\% versus $81 \%), U=105,50, p=0,053$, Delta de Cliff $=-0,43$. Una vez más, no hubo diferencias al comparar el desempeño en cada condición en función de la modalidad semiótica, bimodal, $Z=-1,23, p=0,218, \mathrm{y}$ unimodal, $Z=-1,23, p=0,218$.

En segundo lugar, las comparaciones por grupo de edad revelan un desempeño superior de los niños de 4 años en las dos condiciones experimentales. Al interior de la condición unimodal, el rendimiento a los 4 años fue mejor que a los 3 años con imágenes (81\% versus 50\%), $U=32, p<0,001$, Delta de Cliff $=-0,80, \mathrm{y}$ objetos ( $76 \%$ versus $44 \%$ ), $U=33, p<0,001$, Delta de Cliff $=-0,79$. Constatamos el mismo perfil de resultados en la condición bimodal: los niños mayores se desempeñaron mejor con las dos modalidades semióticas, imágenes/palabras número (90\% versus $65 \%$ ), $U=16,50, p<0,001$, Delta de Cliff $=-0,89$, y objetos/palabras número (87\% versus 65\%), $U=33, p<0,001$, Delta de Cliff $=-0,79$.

Tamaño de las colecciones. Para indagar si esta mejora en el desempeño a partir de la presentación bimodal de la información cuantitativa se relacionaba específicamente con algún valor cardinal, analizamos los efectos de la condición en función del tamaño de las colecciones que los niños podían construir. Como puede observarse en la Tabla 2, la mayor parte de los niños de 3 años de la condición unimodal iterativa se desempeñó como conocedor de dos (39\%), con $28 \%$ y $22 \%$ con un rendimiento exitoso con objetos e imágenes al construir colecciones de hasta 3 y 4 galletas, respectivamente. Este perfil de desempeño se diferencia claramente de la condición bimodal, en la cual los niños se desempeñaron principalmente como conocedores de cuatro (56\%). Los análisis estadísticos de comparación de frecuencias confirman los efectos de la presentación simultánea de representaciones iterativas y palabras número, al aumentar de 2 a 4 el tamaño de las colecciones que los niños de 3 años fueron capaces de construir en la tarea Dame un Número. 
Tabla 2

Desempeño de los Niños de 3 Años en la Tarea Dame un Número, Según Condición Experimental, Unimodal (Iterativa) y Bimodal

\begin{tabular}{|c|c|c|c|c|c|}
\hline \multirow{2}{*}{ Desempeño por valor cardinal } & \multicolumn{2}{|c|}{ Condición ${ }^{1}$} & \multirow{2}{*}{$\chi^{2}$} & \multirow{2}{*}{$g l$} & \multirow{2}{*}{$p$} \\
\hline & Unimodal & Bimodal & & & \\
\hline No conocedor & 1 & 0 & 1,02 & 1 & 0,310 \\
\hline Conocedor de uno & 1 & 0 & 1,02 & 1 & 0,310 \\
\hline Conocedor de dos & 7 & 0 & 8,69 & 1 & 0,003 \\
\hline Conocedor de tres & 5 & 7 & 0,50 & 1 & 0,480 \\
\hline Conocedor de cuatro & 4 & 10 & 4,20 & 1 & 0,040 \\
\hline Conocedor de cinco & 0 & 1 & 1,02 & 1 & 0,310 \\
\hline Conocedor de seis & 0 & 0 & - & - & - \\
\hline
\end{tabular}

${ }^{1}$ Sobre un total de 18 niños en cada condición experimental.

En el grupo de 4 años se registró un efecto similar de la condición experimental (ver Tabla 3). En la condición unimodal, la mayor parte del grupo (56\%) se desempeñó como conocedor de cuatro, ampliándose en la condición bimodal el tamaño de las colecciones que los niños pudieron construir: 50\% de los niños se comportó como conocedor de cinco y 33\%, como conocedor de seis. Las comparaciones de frecuencias revelaron un impacto de la condición, al aumentar de 4 a 6 el tamaño de las colecciones que los niños pudieron construir.

Tabla 3

Desempeño de los Niños de 4 Años en la Tarea Dame un Número, Según Condición Experimental, Unimodal (Iterativa) y Bimodal

\begin{tabular}{lcccccc}
\hline \multirow{2}{*}{ Desempeño por valor cardinal } & \multicolumn{2}{c}{ Condición $^{1}$} & & & \\
\cline { 2 - 3 } & Unimodal & Bimodal & & $\chi^{2}$ & & $p$ \\
\hline No conocedor & 0 & 0 & - & - & - \\
Conocedor de uno & 0 & 0 & - & - & - \\
Conocedor de dos & 1 & 0 & 1,02 & 1 & 0,310 \\
Conocedor de tres & 2 & 0 & 2,11 & 1 & 0,146 \\
Conocedor de cuatro & 10 & 3 & & 5,90 & 1 & 0,015 \\
Conocedor de cinco & 4 & 9 & & 3,01 & 1 & 0,083 \\
Conocedor de seis & 1 & 6 & 4,43 & 1 & 0,035 \\
\hline
\end{tabular}

${ }^{1}$ Sobre un total de 18 niños en cada condición experimental.

Estudio 1 versus Estudio 2. Resultó de interés comparar en cada grupo de edad el desempeño entre las tres condiciones de resolución de la tarea, unimodal palabras número (Estudio 1), unimodal iterativa y bimodal (Estudio 2). A los 3 años, la prueba de Kruskal-Wallis reveló efectos de la condición en la construcción exitosa de colecciones de tamaño $2, \chi^{2}(2, N=19)=17,37, p<0,001, \mathrm{y} 4, \chi^{2}(2, N=16)=9,06, p=0,011$. Los conocedores de dos predominaron en las condiciones palabras número (67\% de los niños) y unimodal iterativa (39\% de los niños), $U=117, p=0,100$, estando ausente esta clase de desempeño en la condición bimodal, $U=54, p<0,001$, Delta de Cliff $=0,66$, y $U=99, p=0,004$, Delta de Cliff $=0,38$, respectivamente. Por el contrario, el porcentaje de niños que se desempeñó como conocedores de cuatro fue más alto en la condición bimodal (56\%), diferenciándose de la condición unimodal iterativa $(22 \%), U=108, p=0,043$, Delta de Cliff $=$ 0,33, y de la condición palabras número (11\%), $U=90, p=0,005$, Delta de Cliff $=0,44$, sin registrarse diferencias entre estas dos últimas condiciones, $U=144, p=0,378$.

A los 4 años, los análisis estadísticos confirman que la forma de presentación de la información cuantitativa también tiene un impacto, pero al construir colecciones de $3, \chi^{2}(2, N=12)=17,66 p<0,001,4$, $\chi^{2}(2, N=16)=8,54 p=0,014,5, \chi^{2}(2, N=13)=5,49, p=0,064$, y 6 elementos, $\chi^{2}(2, N=8)=7,20, p=0,027$. 
Las comparaciones de a pares señalan que el porcentaje de conocedores de tres en la condición palabras número (56\%) fue superior a las dos condiciones restantes, unimodal iterativa ( $11 \%), U=90, p=0,005$, Delta de Cliff $=0,44$, y bimodal (0\%), $U=72, p<0,001$, Delta de Cliff $=0,55$, sin diferencias entre estos dos últimos grupos, $U=144, p=0,151$.

De manera inversa, mientras que en la condición bimodal el 56\% de los niños se desempeñó como conocedores de cuatro, solo el 17\% pudo hacerlo con palabras número y en la condición unimodal iterativa, $U=99, p=0,017$, Delta de Cliff $=0,38$, en ambos casos. Por lo tanto, únicamente la presentación bimodal de la información cuantitativa amplió de 3 a 4 el tamaño de las colecciones que los niños de 4 años fueron capaces de construir.

Aunque para los conocedores de cinco el efecto de la condición es marginal, las comparaciones de a pares revelan un patrón de resultados diferente. Como esperábamos, ningún niño logró construir colecciones de este tamaño en el formato tradicional de la tarea Dame un Número; sin embargo, el $22 \%$ de los niños lo hizo con objetos e imágenes, $U=126, p=0,036$, Delta de Cliff $=-0,22$, y el $50 \%$ con representaciones iterativas junto con palabras número, $U=117, p=0,018$, Delta de Cliff $=-0,50$, sin diferencias entre estas dos últimas condiciones, $U=153, p=0,704$. En consecuencia, en la construcción de colecciones de tamaño 5, las representaciones iterativas, con o sin palabras número, parecerían operar como un andamiaje del desempeño infantil.

Finalmente, aunque un número menor de niños pudo construir exitosamente colecciones de tamaño 6 , su perfil de desempeño fue semejante al grupo conocedores de cuatro. El porcentaje de conocedores de seis de la condición bimodal (33\%) fue mayor que en ambas condiciones unimodales, iterativa (6\%), $U=117, p=0,038$, Delta de Cliff $=0,27$, y palabras número (6\%), $U=117, p=0,038$, Delta de Cliff $=0,27$, también sin diferencias entre las dos condiciones unimodales, $U=162, p>0,999$.

\section{Discusión y Conclusiones}

En estos estudios nos preguntamos si y cómo modos bimodales de presentación de la información cuantitativa mediante la combinación de representaciones permanentes e iterativas (colecciones de objetos y en imágenes) y palabras número impactarían en la comprensión de los primeros números por parte de niños de 3 y 4 años. Los resultados muestran que efectivamente la presentación bimodal contribuyó a un desempeño mejor en la tarea Dame un Número en ambos grupos de edad, en comparación con la presentación a través de cada modo semiótico por separado. Al interior del rango de valores cardinales en juego, los modos bimodales ampliaron de 2 a 4 el tamaño de las colecciones que los niños de 3 años fueron capaces de construir y de colecciones de tamaño 3 a 6 a los 4 años.

La mayor parte de las investigaciones previas se ha centrado en indagar el rol de las palabras número en la adquisición de los conocimientos numéricos tempranos (Le Corre \& Carey, 2007; Sarnecka, 2015; Spaepen et al., 2018; van Marle et al., 2014; Wynn, 1990, 1992, 2018); sin embargo, en sus actividades cotidianas niños y adultos despliegan una multiplicidad de modos semióticos (Kress, 2010) para representar, comunicar y resolver problemas con y sobre números. Desde esta perspectiva, cada modo semiótico posee propiedades específicas que potencian y restringen los procesos de significación y resignificación del número, relacionándose con distintas variables, como la edad de los niños, las demandas de las tareas cuantitativas y el referente que se pretende representar (por ejemplo, cantidades discretas y pequeñas o grandes). Si focalizamos la atención en la edad, nuestros resultados están en línea con los estudios que indican que entre los 3 y los 4 años se produce un progreso notable en la comprensión y el uso de las cantidades 2 a 6 (Baroody et al., 2017, Octubre; Mix, 2002; Mix et al., 2005; Paliwal \& Baroody, 2018). No obstante, los resultados ponen de manifiesto que la modalidad semiótica bajo la cual se transmite a los niños información cuantitativa sería un factor decisivo en su desempeño.

Ahora bien, ¿por qué los modos bimodales tendrían este efecto facilitador en la tarea Dame un Número? Una posibilidad es que sean un apoyo más eficaz, porque crean una representación enriquecida del problema a resolver al combinar representaciones permanentes e iterativas con el etiquetado de sus valores cardinales a través de las palabras número. Por un lado, los objetos y las imágenes promoverían la resolución de la tarea mediante correspondencias uno a uno entre los elementos de la representación y los elementos de la colección a construir (Rodríguez et al., 2018; Salsa \& Martí, 2015). La correspondencia uno a uno es un aspecto central del número y proporciona una manera de determinar equivalencias, ya sea que la correspondencia se establezca directamente entre elementos individuales por emparejamiento o indirectamente, al contar una colección y luego la otra (Fuson, 1988; Mix, Moore \& Holcomb, 2011; Piaget \& Szeminska, 1941). La inclusión 
de objetos e imágenes en la tarea Dame un Número crea un contexto de resolución que fomentaría las comparaciones entre conjuntos y promovería la construcción de colecciones equivalentes por correspondencias que podrían ser fácilmente inspeccionadas, repetidas y modificadas. En este sentido, su incorporación reduciría también las demandas de memoria de trabajo de la tarea. Incluso con cantidades pequeñas, la versión tradicional de la tarea requiere que los niños mantengan la cantidad solicitada en la memoria de trabajo y comparen este valor con el número de elementos de la colección que están construyendo. Los objetos y las imágenes, por su permanencia física y al activar las correspondencias uno a uno, probablemente disminuyen la demanda de memoria de la prueba.

Por otro lado, al etiquetar los valores cardinales de las representaciones permanentes e iterativas con su correspondiente palabra número, el apoyo sería doble. Mix $(1999,2002)$ ha demostrado que los niños se desempeñan mejor en tareas de equivalencia numérica cuando conocen la palabra número para el tamaño de las colecciones involucradas. La etiqueta verbal estimularía un proceso de comparación, como el descripto por Gentner (2005) para el razonamiento por analogía, que favorecería el reconocimiento de la cantidad como un atributo común de los conjuntos que se comparan. En consecuencia, los modos bimodales simplificarían las demandas cognitivas y numéricas de la tarea, ampliando, así, el tamaño de las colecciones que los niños preescolares pueden construir.

Otra posibilidad es que el efecto facilitador de los modos bimodales se deba a la integración temporal de las modalidades semióticas. Este efecto podría interpretarse desde dos enfoques distintos. Primero, uno de los supuestos de las teorías de procesamiento de la información es que los seres humanos poseemos una capacidad de procesamiento limitada en cualquier canal individual, pero puede aumentarse la carga de procesamiento cognitivo tomando información de dos canales a la vez, visual (como es el caso de los objetos y las imágenes) y auditivo-verbal (palabras número) (Baddeley, 1999; Chandler \& Sweller, 1991). Este principio de contigüidad ha sido puesto a prueba en estudios sobre aprendizaje de conceptos matemáticos que han mostrado que información verbal y gestual recibida simultáneamente tiene un impacto mayor que la misma información transmitida por los dos canales pero en forma secuencial (alternando el orden verbal/visual). La combinación de instrucciones verbales y gestuales estimularía a los estudiantes a integrar las ideas transmitidas para crear conceptos nuevos, flexibles y más duraderos (Congdon et al., 2017; Congdon et al., 2018).

Segundo, en la condición bimodal, la integración temporal de las modalidades semióticas determinó que la experimentadora presentara a los niños la información cuantitativa asociando las palabras número con cantidades exactas, representadas en las colecciones de objetos y en imágenes. Estos mapeos no solo serían un paso crítico en la comprensión sobre cómo las representaciones deben ser usadas para denotar valores cardinales, sino que se relacionarían también con la manipulación de cantidades, especialmente de magnitud mayor al rango de subutización 1-3 y estarían en la base de la adquisición de habilidades matemáticas más complejas (Benoit et al., 2013; Hurst et al., 2017; Jiménez Lira, 2016; Jiménez Lira et al., 2017). Entonces, otra posible ventaja de los modos bimodales sería que, al vincularse dos tipos de representaciones (objetos/palabras e imágenes/palabras), los procesos de mapeo promoverían la construcción de colecciones más grandes que las que los niños producirían apoyándose en un único modo semiótico (objetos, imágenes o palabras).

Un patrón de resultados interesante se desprende al comparar entre sí las tres condiciones de resolución de la tarea. A los 3 años, la mayor parte de los niños se desempeñó como conocedores de dos con palabras número y en la condición unimodal iterativa y como conocedores de cuatro en la condición bimodal; a los 4 años, el perfil de desempeño fue desde conocedores de tres con palabras número, ampliándose hasta conocedores de seis en la condición bimodal. Estos datos aportan evidencia empírica nueva acerca de que los niños preescolares comprenderían gradualmente los valores cardinales de acuerdo a la secuencia numérica, pero siguiendo una trayectoria menos estricta y fija que la propuesta por el enfoque de los niveles de conocimiento (Carey, 2009; Sarnecka, 2015; Wynn, 1992, 2018). Variaciones en el contexto de resolución de la tarea en estos estudios, mediante los modos semióticos utilizados para presentar una cantidad a los niños, posibilitarían mostrar el interjuego entre conocimientos cardinales disponibles y emergentes, evidenciando así, tensiones y desfases en el desarrollo numérico temprano, en lugar de una secuencia de etapas fijas del conocimiento.

A su vez, otro resultado que abriría un interrogante al enfoque de los niveles de conocimiento es el desempeño de los niños con las colecciones de 5 y 6 elementos. En la literatura en el área (Sarnecka \& Carey, 2008; Wynn, 2018), el supuesto dominante es que la construcción exitosa de colecciones de 4 desencadenaría un proceso de generalización que posibilitaría la construcción de colecciones de cualquier tamaño dentro del rango de conteo (conocedor cardinal). Varios estudios han mostrado que, por ejemplo, cuando los niños producen colecciones de 4 elementos, la mayor parte $(87,50 \%)$ de esos niños produce también colecciones de 
tamaño 5 y 6 (Geary \& vanMarle, 2018). De modo similar a los resultados de nuestros estudios, otras investigaciones (Le Corre \& Carey, 2007) han reportado datos opuestos: los niños que fueron capaces de producir colecciones de tamaño 4, no fueron luego necesariamente exitosos con los tamaños 5 y 6. Cuándo y cómo considerar que los niños dominan el principio de cardinalidad en la tarea Dame un Número es eje de debates actuales: este perfil de resultados sobre cómo la modalidad semiótica determinaría diferentes patrones de desempeño con los valores cardinales mayores que 4 requiere profundización en futuras investigaciones, empleando muestras más grandes, ya que el tamaño reducido de la muestra fue una limitación de nuestros estudios, y ampliando el rango de edad de los niños hasta aproximadamente los 5 años.

Otros aspectos necesitan también tenerse en cuenta en estudios futuros para obtener una imagen más completa de las trayectorias numéricas que hemos descrito aquí. El empleo de diseños intrasujetos, donde un mismo niño resuelva la tarea Dame un Número en las condiciones unimodales y bimodales, aportaría evidencia más firme sobre cómo los aspectos semióticos de la cantidad son claves en el desempeño, principalmente con valores cardinales mayores que 4. Nuestra investigación está potencialmente limitada por el uso de una única tarea, cuando es ampliamente aceptado que las variaciones en las demandas de las pruebas afectan el desempeño infantil (Baroody et al., 2017, Octubre; Le Corre \& Carey, 2007; Sarnecka \& Carey, 2008). Una dirección crucial para el trabajo futuro será explorar la influencia de los modos semióticos iterativos y bimodales en la adaptación de otras tareas como ¿Cuántos hay? o Señala $X$, para examinar si la ventaja de estas modalidades sobre las palabras número se mantendría a través de diversas tareas cuantitativas.

Finalmente, una comprensión profunda sobre cómo los niños aprenden a manejar situaciones numéricas y de qué forma los modos semióticos dan soporte a la adquisición de conocimientos nuevos constituye un aspecto crucial para el diseño y la implementación de acciones educativas. Por ejemplo, ayudar a los niños en edad preescolar a integrar sus conocimientos sobre la cantidad, las palabras número y otras representaciones tendría efectos facilitadores en la adquisición de habilidades matemáticas en su escolarización formal (Jiménez Lira, 2016).

Con respecto a los objetos y las imágenes, el empleo de material concreto como representación del número posee una tradición fuerte en psicología y educación, bajo el supuesto de que es más sencillo para los niños comprender ciertos conceptos en entornos ricos en experiencias con elementos concretos que hacerlo sin este apoyo material (Baroody, 2017; Fyfe \& Nathan, 2019). Este tipo de propuesta plantea el trabajo de aula a partir de objetos manipulables y actividades, por ejemplo, de seriación, clasificación, correspondencia y operaciones. Los resultados de nuestros estudios contribuirán a que los educadores reflexionen sobre las propiedades de cada material y sus complejidades semióticas antes de planificar su empleo sistemático en estas actividades. Además, como hemos intentado demostrar, no solo las propiedades de las representaciones cuentan, sino también cómo se presentan a los niños, en modos unimodales o bimodales: el uso simultáneo de representaciones permanentes e iterativas y palabras número permitiría aprovechar al máximo las oportunidades de aprendizaje que estas representaciones brindan a la hora de resolver problemas con y sobre números.

\section{Referencias}

Anders, Y., Rossbach, H. -G., Weinert, S., Ebert, S., Kuger, S., Lehrl, S. \& von Maurice, J. (2012). Home and preschool learning environments and their relations to the development of early numeracy skills. Early Childhood Research Quarterly, 27, 231-244. https://doi.org/10.1016/j.ecresq.2011.08.003

Baddeley, A. (1999). Human memory: Theory and practice (2a reimpresión). Boston, MA: Allyn \& Bacon.

Baroody, A. J. (2017). The use of concrete experiences in early childhood mathematics instruction. Advances in Child Development and Behavior, 53, 43-94. https://doi.org/10.1016/bs.acdb.2017.03.001

Baroody, A. J., Lai, M. -L. \& Mix, K. S. (2017, Octubre). Assessing early cardinal-number concepts. Ponencia presentada en la ThirtyNinth Annual Meeting of the North American Chapter of the International Group for the Psychology of Mathematics Education, Indianapolis, IN, Estados Unidos. Extraído de: https://www.researchgate.net/publication/316842100_Assessing_Early_CardinalNumber_Concepts\#fullTextFileContent

Benoit, L., Lehalle, H., Molina, M., Tijus, C. \& Jouen, F. (2013). Young children's mapping between arrays, number words, and digits. Cognition, 129, 95-101. https://doi.org/10.1016/j.cognition.2013.06.005

Carey, S. (2009). The origin of concepts. New York, NY: Oxford University Press.

Chandler, P. \& Sweller, J. (1991). Cognitive load theory and the format of instruction. Cognition and Instruction, 8, 293-332. https://doi.org/10.1207/s1532690xci0804_2

Congdon, E. L., Kwon, M. -K. \& Levine, S. C. (2018). Learning to measure through action and gesture: Children's prior knowledge matters. Cognition, 180, 182-190. https://doi.org/10.1016/j.cognition.2018.07.002

Congdon, E. L., Novack, M. A., Brooks, N., Hermani-López, N., O'Keefe, L. \& Goldin-Meadow, S. (2017). Better together: Simultaneous presentation of speech and gesture in math instruction supports generalization and retention. Learning and Instruction, 50, 65-74. https://doi.org/10.1016/j.learninstruc.2017.03.005 
DeLoache, J. S. (1995). Early understanding and use of symbols: The model model. Current Directions in Psychological Science, 4, 109113. https://doi.org/10.1111/1467-8721.ep10772408

Fuson, K. C. (1988). Children's counting and concepts of number. New York, NY: Springer-Verlag. https://doi.org/10.1007/978-1-4612-3754-9

Fyfe, E. R. \& Nathan, M. J. (2019). Making "concreteness fading" more concrete as a theory of instruction for promoting transfer. Educational Review, 71, 403-422. https://doi.org/10.1080/00131911.2018.1424116

Geary, D. C. \& vanMarle, K. (2018). Growth of symbolic number knowledge accelerates after children understand cardinality. Cognition, 177, 69-78. https://doi.org/10.1016/j.cognition.2018.04.002

Gelman, R. \& Gallistel, C. R. (1978). The child's understanding of number. Cambridge, MA: Harvard University Press.

Gentner, D. (2005). The development of relational category knowledge. En L. Gershkoff-Stowe \& D. H. Rakison (Eds.), Building object categories in developmental time (pp. 245-275). Mahwah, NJ: Lawrence Erlbaum.

Gibson, D. J., Gunderson, E. A., Spaepen, E., Levine, S. C. \& Goldin-Meadow, S. (2019). Number gestures predict learning of number words. Developmental Science, 22(3), artículo e12791. https://doi.org/10.1111/desc.12791

Gunderson E. A., Spaepen, E., Gibson, D., Goldin-Meadow, S. \& Levine, S. C. (2015). Gesture as a window onto children's number knowledge. Cognition, 144, 14-28. https://doi.org/10.1016/j.cognition.2015.07.008

Hurst, M., Anderson, U. \& Cordes, S. (2017). Mapping among number words, numerals, and nonsymbolic quantities in preschoolers. Journal of Cognition and Development, 18, 41-62. https://doi.org/10.1080/15248372.2016.1228653

Jiménez Lira, C. (2016). Children's acquisition of the mappings among the number representations (Tesis de Doctorado, Carleton University, Ottawa, Canadá). Extraído de: https://curve.carleton.ca/5635ab88-f9ce-44b7-8fff-c9743439bb29

Jiménez Lira, C., Carver, M., Douglas, H. \& LeFevre, J. -A. (2017). The integration of symbolic and non-symbolic representations of exact quantity in preschool children. Cognition, 166, 382-397. https://doi.org/10.1016/j.cognition.2017.05.033

Kress, G. R. (2010). Multimodality: A social semiotic approach to contemporary communication. London: RoutledgeFalmer.

Le Corre, M. \& Carey, S. (2007). One, two, three, four, nothing more: An investigation of the conceptual sources of the verbal counting principles. Cognition, 105, 395-438. https://doi.org/10.1016/j.cognition.2006.10.005

Le Corre, M., Van de Walle, G., Brannon, E. M. \& Carey, S. (2006) Re-visiting the competence/performance debate in the acquisition of the counting principles. Cognitive Psychology, 52, 130-169. https://doi.org/ 10.1016/j.cogpsych.2005.07.002

Martí, E. (2012). Thinking with signs: From symbolic actions to external systems of representation. En E. Martí \& C. Rodríguez (Eds.), After Piaget (pp. 151-170). New Brunswick, NJ: Transaction Publishers.

Martí, E. \& Scheuer, N. (2015). Sistemas semióticos, cultura y conocimiento matemático temprano. Estudios de Psicología, 36, 9-17. https://doi.org/10.1080/02109395.2014.1000008

Martí, E., Scheuer, N., Cavalcante, S., Trench, M. \& Brizuela, B. M. (2016). Symbolic representation of the number three: A study with three-year-old children from contrasting socioeconomic environments. Journal of Cognitive Psychology, 28, 743-755. https://doi.org/10.1080/20445911.2016.1188821

Mayer, R. E. (2002). Multimedia learning. Psychology of Learning and Motivation, 41, 85-139. https://doi.org/10.1016/S0079-7421(02)80005-6

Mayer, R. E. \& Moreno, R. (2003). Nine ways to reduce cognitive load in multimedia learning. Educational Psychologist, 38, 43-52. https://doi.org/10.1207/S15326985EP3801_6

Mix, K. S. (1999). Preschoolers' recognition of numerical equivalence: Sequential sets. Journal of Experimental Child Psychology, 74, 309-332. https://doi.org/10.1006/jecp.1999.2533

Mix, K. S. (2002). The construction of number concepts. Cognitive Development, 17, 1345-1363. https://doi.org/10.1016/S0885-2014(02)00123-5

Mix, K. S., Moore, J. A. \& Holcomb, E. (2011). One-to-one play promotes numerical equivalence concepts. Journal of Cognition and Development, 12, 463-480. https://doi.org/10.1080/15248372.2011.554928

Mix, K. S., Sandhofer, C. M. \& Baroody, A. J. (2005). Number words and number concepts: The interplay of verbal and nonverbal quantification in early childhood. Advances in Child Development and Behavior, 33, 305-346. https://doi.org/10.1016/S0065-2407(05)80011-4

Nicoladis, E., Pika, S. \& Marentette, P. (2010). Are number gestures easier than number words for preschoolers? Cognitive Development, 25, 247-261. https://doi.org/10.1016/j.cogdev.2010.04.001

Paliwal, V. \& Baroody, A. J. (2018). How best to teach the cardinality principle? Early Childhood Research Quarterly, 44, 152-160. https://doi.org/10.1016/j.ecresq.2018.03.012

Petersen, L. A., McNeil, N. M., Tollaksen, A. K., Boehm, A. G., Hall, C. J., Carrazza, C. \& Devlin, B. L. (2014). Counting practice with pictures, but not objects, improves children's understanding of cardinality. En P. Bello, M. Guarini, M. McShane \& B. Scassellati (Eds.), Proceedings of the $36^{\text {th }}$ Annual Meeting of the Cognitive Science Society (pp. 2633-2637). Austin, TX: Cognitive Science Society.

Piaget, J. \& Szeminska, A. (1941). La genèse du nombre chez l'enfant (La génesis del número en el niño) Neuchâtel, Suiza: Delachaux et Niestlé.

Rodríguez, J., Martí, E. \& Salsa, A. (2016). La naturaleza semiótica de los conocimientos numéricos: aportes al campo de la educación. Revista de Psicología de la Pontificia Universidad Católica Argentina, 12(23), 66-79. Extraído de: https://repositorio.uca.edu.ar/bitstream/123456789/6141/1/naturaleza-semiotica-conocimientos-numericos.pdf

Rodríguez, J., Martí, E. \& Salsa, A. (2018). Symbolic representations and cardinal knowledge in 3- and 4-year-old children. Cognitive Development, 48, 235-243. https://doi.org/10.1016/j.cogdev.2018.09.004

Salsa, A. M. \& Martí, E. (2015). Objects, pictures and words. Effects of representational format on four-year-olds' quantity knowledge. Estudios de Psicología, 36, 81-91. https://doi.org/10.1080/02109395.2014.1000031

Sarnecka, B. W. (2015). Learning to represent exact numbers. Synthese, 1-18. Publicado en línea. https://doi.org/10.1007/s11229-0150854-6. Extraído de: https://escholarship.org/uc/item/6tq9j73k

Sarnecka, B. W. \& Carey, S. (2008). How counting represents number: What children must learn and when they learn it. Cognition, 108, 662-674. https://doi.org/10.1016/j.cognition.2008.05.007

Sarnecka, B. W. \& Lee, M. D. (2009). Levels of number knowledge during early childhood. Journal of Experimental Child Psychology, 103, 325-337. https://doi.org/10.1016/j.jecp.2009.02.007

Spaepen, E., Gunderson, E. A., Gibson, D., Goldin-Meadow, S. \& Levine, S. C. (2018). Meaning before order: Cardinal principle knowledge predicts improvement in understanding the successor principle and exact ordering. Cognition, 180, 59-81. https://doi.org/10.1016/j.cognition.2018.06.012

Tolchinsky, L. (2003). The cradle of culture and what children know about writing and numbers before being taught. Mahwah, NJ: Lawrence Erlbaum.

Uttal, D. H., Liu, L. L. \& DeLoache, J. S. (2006). Concreteness and symbolic development. En L. Balter \& C. S. Tamis-Lemonda (Eds.), Child psychology: A handbook of contemporary issues (pp. 167-184). Philadelphia, PA: Psychology Press. 
Uttal, D. H., O'Doherty, K., Newland, R., Hand, L. L. \& DeLoache, J. (2009). Dual representation and the linking of concrete and symbolic representations. Child Development Perspectives, 3, 156-159. https://doi.org/10.1111/j.1750-8606.2009.00097.x

van Marle, K., Chu, F. W., Li, Y. \& Geary, D. C. (2014). Acuity of the approximate number system and preschoolers' quantitative development. Developmental Science, 17, 492-505. https://doi.org/10.1111/desc. 12143

Wynn, K. (1990). Children's understanding of counting. Cognition, 36, 155-193. https://doi.org/10.1016/0010-0277(90)90003-3

Wynn, K. (1992). Children's acquisition of the number words and the counting system. Cognitive Psychology, 24, $220-251$. https://doi.org/10.1016/0010-0285(92)90008-P

Wynn, K. (2018). Origins of numerical knowledge. En S. Bangu (Ed.), Naturalizing logico-mathematical knowledge: Approaches from philosophy, psychology, and cognitive science (pp. 106-130). New York, NY: Routledge.

Fecha de recepción: Enero de 2019.

Fecha de aceptación: Noviembre de 2019. 